though this would be expected to be balanced by effective antihypertensive treatment.

Necropsy reports on some of the cadaveric kidney donors were kindly provided by the departments of pathology at the following hospitals: Hvidovre Hospital; the State University Hospital of Copenhagen Bispebjerg Hospital; Odense Hospital; Århus Municipal Hospital; and Esbjerg Hospital; and the Institute of Forensic Medicine at the University of Copenhagen, Denmark. Clinical data on some of the transplant recipients were kindly provided by the departments of nephrology at Hvidovre Hospital, Odense Hospital, Århus Municipal Hospital, and Ålborg Hospital South, Denmark. Dr Birger Broch Møller gave valuable advice on the statistical handling of the data.

\section{References}

I McDonald FD, Brennan LA, Turcotte JG. Severe hypertension and elevated plasma renin activity following transplantation of "hepatorenal donor" kidneys into anephric recipients. Am f Med 1973;54:39-43.
2 Merino GE, Kjellstrand CM, Sammons RL, Najarian JS. Late hypertension in renal transplant recipients: possible role of the donor in late primary hypertension. Proc Dial Transplant Forum 1976;6: 145-53

3 Bianchi G, Fox UD, Francesco GF, et al. Blood pressure changes produced by kidney crosstransplantation between spontaneously hypertensive rats and normotensive rats. Clinical Science and Molecular Medicine 1974;47:435-48.

4 Amad KH, Brennan JC, Alexander JK. The cardiac pathology of chronic exogenous obesity. Circulation 1965;32:740-5.

5 Smith HL. The relation of the weight of the heart to the weight of the body and of the weight of the heart to age. Am Heart f 1928;4:79-93.

6 Stebhens WE. The pathology of intracranial arterial aneurysms and their complications. In: Fox JL, ed. Intracranial aneurysms. New York, Berlin, Heidelberg: Springer-Verlag, 1983.272-357. Jacquot $C$, Idatte J-M, Bedrossian J et al. Long term blood pressure changes in rel homotransplantation. Arch Intern Med 1978;138:233-6.

Bachy C, Alexandre GPJ, de Strihou CvanY. Hypertension after renal transplantation. Br Med $\mathcal{f} \varrho$ 1976;ii:1287-9.

de Strihou CvanY, Vereerstraeten $P, W$ anthier $M$, et al. Prevalence, etiology and treatment of late $\overrightarrow{\vec{F}}$ posttransplant hypertension. Adv Nephrol 1983;12:41-60.

10 Tejani A. Post-transplant hypertension and hypertensive encephalopathy in renal allograft recipients. Nephron 1983;34:73-8.

11 Curtis JJ, Luke RG, Dustan HP, et al. Remission of essential hypertension after renal transplantation. N Engl f Med 1983;309: 1009-15.

12 Guidi E, Bianchi G, Rivolta E, et al. Hypertension in man with a kidney transplant: role of familial versus other factors. Nephron 1985;41:14-21.

Accepted 4 February 1986)

\title{
Antibody response and clinical reactions in children given measles vaccine with immunoglobulin
}

\author{
S LINGAM, C L MILLER, MAIRIN CLARKE, JANE PATEMAN
}

\begin{abstract}
Antibody responses and clinical reactions to three measles vaccines (Attenuvax, Mevilin, and Rimevax) injected into the opposite arm to immunoglobulin were assessed in 45 children with brain disorders making them susceptible to fits if given measles vaccine alone.

In this small study no unacceptable reactions occurred and in only three cases was the antibody response minimal or absent.

More children in this special category should be considered for vaccination against measles in this way.
\end{abstract}

\section{Introduction}

When measles vaccine was licensed in the United States in 1963 the only live vaccine available was the Enders Edmonston B strain, which produced unacceptable clinical reactions in up to $60 \%$ of children. With the aim of reducing these reactions standardised measles immunoglobulin was given at the same time in a different site. Though the antibody response was slightly reduced it nevertheless persisted for up to three years. ${ }^{1}$ Between 1963 and 1965 in the United States some 5 million doses of Edmonston B vaccine were distributed each year with the official recommendation that immunoglobulin should be given simultaneously.

King George Hospital, llford, Essex

S LINGAM, MD, MRCP, consultant paediatrician

PHLS Communicable Disease Surveillance Centre, Colindale, London NW9 C L MILLER, BM, MFCM, senior epidemiologist

National Institute for Biological Standards and Control, Hampstead, London NW 3

MAIRIN CLARKE, $\mathrm{MB}, \mathrm{BCH}$, scientific staff, division of viral products

Redbridge Health Authority, Ilford, Essex

JANE PATEMAN, SRN, nursing officer in community health

Correspondence to: Dr Miller.
The antibody response to vaccines given with small doses of immunoglobulin was reported in Britain in $1964 .^{2}$ The three vaccines were Edmonston $B$, Edmonston $A$ after 65 further passages, and Edmonston $B$ after 30 passages. The conclusion was that the reactions were mild and the antibody response satisfactory when these vaccines were given with immunoglobulin but that the vaccines were not suitable for use alone.

At present in Britain three further attenuated vaccines are in use: Mevilin (Evans Medical), Rimevax (Smith Kline and French), and Attenuvax (Merck Sharp and Dohme) (fig 1). Concurrent immunoglobulin is now recommended by the Department of Health only for children with a personal history of convulsions or a close family history of non-traumatic epilepsy. ${ }^{3}$ We have assessed the antibody responses and clinical reactions to current measles vaccines given with immunoglobulin in children in whom measles vaccine alone was contraindicated.

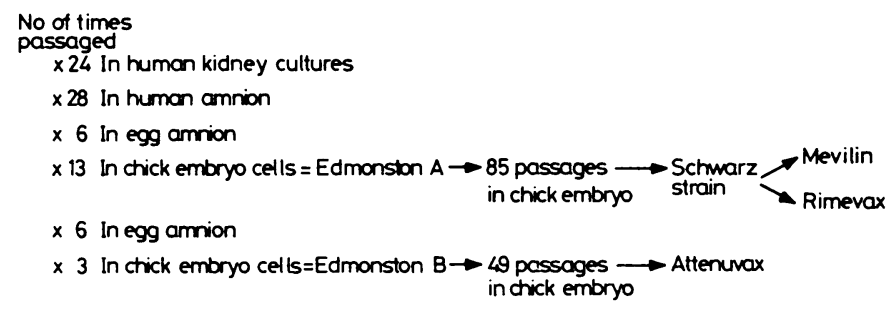

FIG 1-Derivation of measles vaccines (measles virus isolated from Edmonston strain by Enders)

\section{Subjects and methods}

Forty five children aged between 1 and 3 years were included in the study, 19 at The Hospital for Sick Children, Great Ormond Street, London, and 26 at the Immunisation Advisory Clinic, Barkingside. All had a history of convulsions, fits in the neonatal period, or other relevant neurological 8 disorders. Twelve received Attenuvax, seven Mevilin, and 26 Rimevax. Serum samples were taken before vaccination and not less than eight weeks after vaccination. The recommended dose of normal immunoglobulin 
for use with measles vaccine $(0 \cdot 4-0 \cdot 8 \mathrm{IU} / \mathrm{kg}$ body weight; Blood Products Laboratory) was given in the opposite arm with a separate syringe immediately after the vaccine was injected. The measles haemagglutination inhibition antibody response was estimated in the paired sera by $\mathrm{MC}$ as described previously. ${ }^{4}$

\section{Results}

Antibody response-Figure 2 shows the haemagglutination inhibition antibody responses at eight weeks. One child (given Rimevax) failed to respond (titre $<4$ ) and two children had a minimal response $(4)$, one after Attenuvax and one after Mevilin.

Clinical reactions-Two reactions were reported after Rimevax. One child with left hemiplegia and a porencephalic cyst associated with dilatation of the right lateral ventricle had a fit five days after vaccination. This was not associated with fever and lasted for a few minutes during which his eyes rolled and he twitched; there had been no similar occurrence. He recovered immediately with no further episodes. Another child with microcephaly and cerebral palsy became febrile and irritable with a cough five days after vaccination but the next day was afebrile. Two children given Attenuvax were reported to have had rashes, one accompanied by coryza. No other reactions were reported.

\section{Discussion}

The 45 children in this study undoubtedly required protection from measles and because of their personal history were considered at risk of having a convulsion from a febrile response to the vaccine given alone. The one fit reported was not associated with fever and occurred in a child with a grossly abnormal brain. Clearly in this small study no unacceptable reactions occurred despite the increased risk.

Since it is not justifiable to take two blood samples from children routinely given measles vaccine any comparison of antibody response must be made with results from an earlier study. In a Medical Research Council trial in 1964,45 children aged 10 months to 2 years were bled before and after being given Schwarz strain vaccine. The response to the vaccine without immunoglobulin was significantly higher (5\% level or beyond), confirming that the antibody response is modified by immunoglobulin. All but one of the children in our study, however, produced a response; only clinical follow up will determine protection.

Modifying possible febrile reactions to further attenuated vaccines by using immunoglobulin is not considered necessary outside Britain. Nevertheless, if the current recommendation results in the vaccination of children such as these it seems justified, since without it they would have remained unvaccinated and at risk.

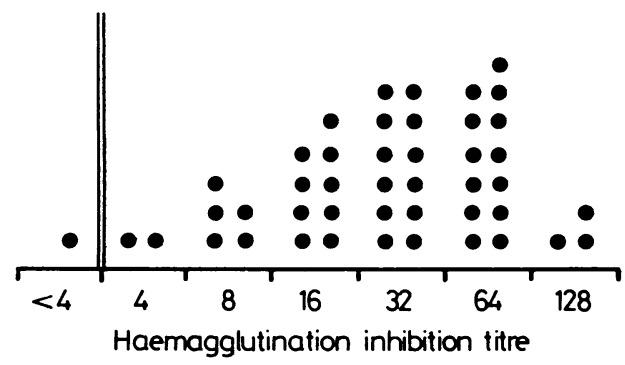

FIG 2-Measles haemagglutination inhibition antibody responses in children given measles vaccine with immunoglobulin.

The amount of specially diluted immunoglobulin for use with measles vaccine supplied by the Blood Products Laboratory trebled between 1983 and 1985, and discrepancies among vaccine manufacturers in the recommendations for its use and dosage have recently been eliminated. We hope that in future more children in these special categories will be vaccinated against measles.

\section{References}

1 Communicable Disease Surveillance Centre. Recommendations of Public Health Advisory Committee on immunisation practice. Morbidity and Mortality Weekly Report 1965 July 14:64.

2 Benson PF, Butler NR, Goffe AP, et al. Vaccination of infants with living attenuated measles vaccine (Edmonston strain) with and without gamma-globulin. Br Med f 1964;ii:851-3.

vepartment of Health and Social Security. Immunisation against infectious diseases. London: HMSO, 1984

4 Medical Research Council Measles Vaccination Committee. Vaccination against measles: a study of clinical reactions and serological response of young children. Br Med $\mathcal{F} 1965 ; 1: 817-23$.

(Accepted 11 March 1986)

\title{
Dose response of patients to oral corticosteroid treatment during exacerbations of asthma
}

\author{
JONATHAN R WEBB
}

\begin{abstract}
Ten patients with asthma were treated with different doses of oral corticosteroids during three separate exacerbations. Prednisolone was given in doses of $0.2,0.4$, and $0.6 \mathrm{mg} / \mathrm{kg}$ body weight daily for two weeks in a double blind randomised order (equivalent to 14, 28, and $42 \mathrm{mg}$ of prednisolone daily in a person weighing $70 \mathrm{~kg}$ ). Patients developing an exacerbation recorded peak expiratory flow rate twice daily for two days before starting and two weeks during treatment. A dose response was shown that was significant for the difference between the peak flows, low dose $<$ medium dose $(\mathbf{p}<\mathbf{0 . 0 0 5})$, medium dose $<$ high dose $(p<0.001)$ at the end of treatment.
\end{abstract}

Regional Respiratory Laboratory, Brook Hospital, London SE18 4LW JONATHAN R WEBB, MRCP, consultant physician
These results confirm the value of treatment with oral corticosteroids in exacerbations of asthma not requiring admission to hospital and indicate that a short high dose course of corticosteroids should consist of a minimum dose of $0.6 \mathrm{mg}$ prednisolone/kg body weight for a period up to two weeks.

\section{Introduction}

The value of treatment with corticosteroids in patients with asthma was first reported in $1949 .{ }^{1}$ There followed similar uncontrolled reports confirming their short term value. The Medical Research Council (MRC) published two controlled studies in $1956^{23}$; in one corticosteroid treatment for acute severe asthma was beneficial, but the second trial of treatment for chronic asthma over a period of six months showed that long term treatment with oral corticosteroids conferred no advantage. Other reports, however, showed that oral 